\title{
FORMULAÇÃo dE UMA HIPÓTESE GLOBAL DE SITUAÇÃo DE IMPACTO PARA O PARQUE INDUSTRIAL PESQUEIRO INSTALADO EM Itajaí e Navegantes - SC
}

\author{
FORMULATION OF A GLOBAL HYPOTHESIS OF IMPACT SITUATION FOR THE \\ FISHING INDUSTRIAL PARK IN ITAJAí AND NAVEGANTES - SANTA CATARINA \\ STATE, SOUTHERN BRAZIL
}

\section{RESUMO}

Para identificar e caracterizar os eventos ambientais decorrentes das operaçōes do parque industrial de Itajaí e Navegantes, em Santa Catarina, utilizou-se o Modelo de Avaliação e Gestão de Impactos Ambientais - MAGIA, como base para a formulação de uma Hipótese Global de Situação de Impacto - HGSI. As principais alterações/aspectos ambientais identificados foram geração de empregos e indução ao dinamismo econômico, geração de resíduos sólidos, efluentes e emissōes para atmosfera; uso ineficiente de insumos e matéria prima; e sazonalidade da ocupação da mão de obra. As consequiências ou impactos associados referem-se à redução da qualidade da água e do ar, ao aumento de descartes orgânicos, ao aumento do uso da água e energia, e ao aumento de episódios de desemprego. Portanto, observa-se a necessidade de uma orientação voltada à gestão ambiental das empresas do setor.
\end{abstract}

LUCIANA DE CARVALHO SPILLERE

Mestre em Ciência e Tecnologia Ambiental pela Universidade do Vale do Itajaí - UNIVALI.

Analista Ambiental do Instituto Brasileiro do Meio Ambiente e dos Recursos Naturais Renováveis - IBAMA

\section{Antonio CARLos BEAUMord}

Doutor em Ecologia, Evolução e Biologia Marinha pela Universidade da California, Santa Barbara - UCSB. Docente Pesquisador do Centro de Ciências da Terra e do Mar - CTTMar, da Universidade do Vale do Itajaí - UNIVALI

Recebido: 21/09/05 Aceito: 10/10/06
PALAVRAS-CHAVE: Avaliação de impacto ambiental, gestão ambiental, indústria pesqueira.

\begin{abstract}
The industrial park of Itajai and Navegantes, in Santa Catarina State, Southern Brazil was selected as a case of study, for purpose, the Model of Evaluation and Management of Environmental Impacts - MAGIA, was used, allowing the formulation of a Global Hypothesis of Impact Situation - HGSI. The main environmental aspects observed were job opportunities and economic dynamics, as well as production of solid wastes, sewage, and air emissions, inefficiency in the use of raw products, and seasonality of man labor. As consequences of such aspects it was observed the impacts variation of man labor offer, reduction of water and air quality, increase of organic discards, and water and energy uses. Therefore, it is strongly recommended the creation of an environmental management policy for the fishing sector.
\end{abstract}

KEYWORDS: Environmental impact assessment, environmental management, fishing industries

\section{INTRODUÇÃO}

A sociedade tem voltado cada vez mais sua atenção para questōes ambientais. Existe uma tendência mundial dos consumidores não se preocuparem apenas com a qualidade dos produtos, mas também com a responsabilidade com que os fabricantes demonstram na elaboração dos seus produtos: alguns consumidores pagam mais por produtos de empresas que não causam danos ao meio ambiente (Sobral et al, 2004). A gestão ambiental se enquadra justamente neste novo conceito da sociedade mundial em que as empresas passam a buscar uma melhoria contínua de seus produtos, no que se refere à qualidade, ao desenvolvimento sustentável e a redução de impactos negativos, para terem uma imagem positiva, junto aos consumidores de seus produtos.

Uma das primeiras iniciativas para se instalar um plano de gestão ambiental em uma empresa é a realização de uma análise ambiental, formulando-se uma hipótese preliminar de situaçōes de impactos ambientais, considerandose requisitos técnicos, econômicos e financeiros de forma a obter as melhores alternativas ambientais para minimizar os impactos negativos, e otimizar ou potencializar os positivos (Kohn de Macedo, 1994).

Nos municípios de Itajaí e Navegantes, o setor pesqueiro é o que mais se destaca. Porém, além das questôes ambientais verificadas em mar aberto, como a sobreexplotação dos recursos, e o manuseio inadequado, que provoca perdas expressivas em relação ao volume do produto ou à qualidade da matéria prima destinada à industrialização (Rebelo Neto, 1989), existem também situaçōes em terra, onde está instalado o parque industrial. Estas situações não deixam de influenciar e/ou transformar o ambiente, no sentido amplo do 
conceito, e são raramente abordadas, e muito menos gerenciadas sob o ponto de vista da eficiência ambiental.

Portanto, este trabalho teve como objetivo formular uma Hipótese Global de Situação de Impacto - HGSI, preconizada no Modelo de Avaliação e Gestão de Impactos Ambientais - MAGIA, estabelecendo-se de forma conceitual as relações de causa e efeito existentes entre as atividades transformadoras do meio, e as alteraçôes e impactos delas decorrentes (Kohn de Macedo 1994).

\section{MÉTODOS}

Primeiramente definiu-se a área de estudo, em função da localização das indústrias nos dois municípios (Figura 1). Para os meios físico e biótico considerou-se como área de influência o Estuário do rio Itajaí, e o ambiente marinho imediatamente adjacente à foz do rio, e para o meio sócio-econômico os municípios de Navegantes e Itajaí.

Itajaí é uma das cidades portuárias mais importantes do país, e foi em torno do porto que a cidade cresceu e desenvolveu o seu parque industrial. A indústria do pescado representa 30\% do total do parque industrial. Os municípios de Itajaí e Navegantes possuem uma estreita relação histórica, visto que Navegantes, até o início da década de 1960, era Distrito de Itajaí. Nos últimos anos, entretanto, Navegantes obteve um desenvolvimento acentuado por fatores de natureza econômica, tais como a vinda de inúmeras empresas que estão se instalando em seu ainda pequeno parque industrial (PROMAR, 2004).
A segunda etapa foi a elaboração de um questionário, distribuído entre as empresas de pesca, em que foram abordados aspectos ambientais e sócio-econômicos, referentes a controle gerencial, gestão de efluentes líquidos, de resíduos sólidos, de emissóes para a atmosfera, e informações sobre a operação da indústria. De um total de 39 questionários distribuídos, 23 empresas responderam, sendo destas, doze de captura, dez de processamento, e uma de comercialização.

Das indústrias que responderam ao questionário, foram selecionadas uma de pequeno, uma de médio e uma de grande porte que trabalhavam com processamento e comercialização, para a realização de visitas técnicas. $\mathrm{O}$ intuito destas visitas foi o de averiguar as informaçōes contidas nas respostas dos questionários, e obter conhecimento do processo produtivo, o que auxiliou na identificação das vulnerabilidades e potencialidades ambientais relacionadas à operação e manutenção destas indústrias. Também foram visitados o Aterro Sanitário Municipal de Itajaí e uma Indústria Farinheira para se conhecer o destino dos resíduos oriundos do setor pesqueiro.

A terceira etapa foi a utilização do método denominado Modelo de Avaliação e Gestão de Impacto Ambiental MAGIA. Este método foi desenvolvido por Kohn de Macedo no final da década de 1980, e foi amplamente utilizado em processos de licenciamentos ambientais em empreendimentos de naturezas diversas. Esta abordagem, juntamente com o software Instrumento para De- senvolvimento de Estudos Ambientais - IDEA, representou um grande avanço em termos de métodos de avaliação de impactos, planejamento e formulação de cenários ambientais, bem como na realização de práticas de monitoramento, controle e gestão ambientais.

Aplicando-se a abordagem do MAGIA, foi então elaborada primeiramente, a imagem do quadro ambiental ocorrente para facilitar o entendimento das relaçôes causa e efeito, e assim, obter as implicações e inter-relaçôes sócio-econômicas e ambientais decorrentes da operação do parque industrial pesqueiro. Depois, conforme postulado no MAGIA, foi realizada a identificação dos eventos ambientais, responsáveis pela atividade transformadora do meio, que é o processo capaz de alterar o ecossistema, seja este processo antropogênico ou não. A atividade transformadora acarreta pelo menos 3 tipos de eventos ambientais: as intervenções ambientais - INAs, que são as açôes de operação ou tarefas verificadas na atividade, no caso, o parque industrial; as alterações ambientais - ALAs, que são os aspectos ambientais envolvidos ou modificações geradas no ambiente pela operação do parque industrial; e os fenômenos ambientais - FEAs, que são os efeitos decorrentes esperados, ou potenciais impactos ambientais.

As intervençōes ambientais (INA) constituem-se em quaisquer ações concretas ou virtuais, permanentes ou temporárias, de pelo menos um fator ambiental de cunho antropogênico em um dado ambiente capaz de gerar ou induzir o manejo de fatores (como

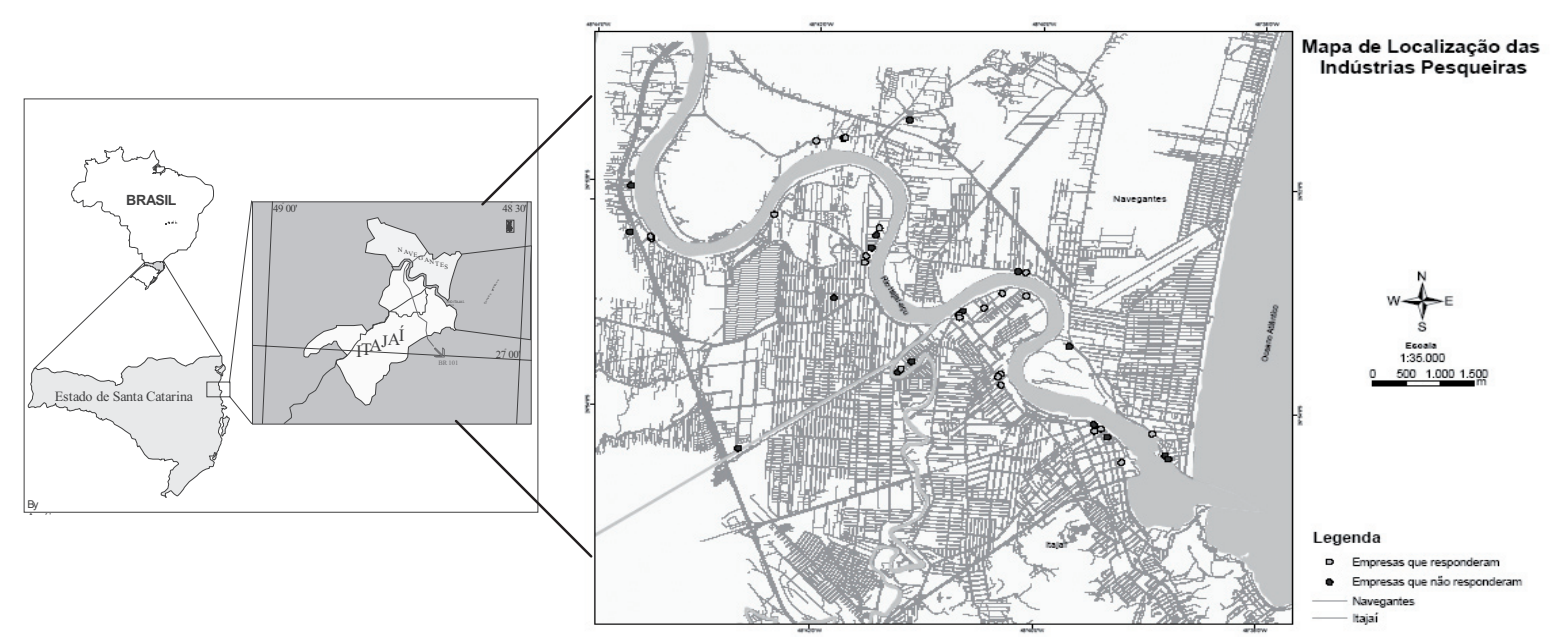

Figura I - Localização da área de estudo, mostrando as cidade de Itajaí e Navegantes, em Santa Catarina, e a localização das indústrias de pesca 
água, ar, solo, flora, fauna e homem) existentes no meio (Kohn de Macedo, 1994). As alteraçôes ambientais (ALAs) consistem no remanejamento espontâneo ou induzido, físico ou funcional, de conjuntos de fatores ambientais ocorrentes na área de influência do empreendimento, em decorrência da introdução de ao menos uma intervenção ambiental no meio. Ou seja, são os aspectos ambientais ou modificaçôes geradas no ambiente, neste caso pela operação do empreendimento, ou a primeira fase de transformaçóes que ocorreram ou que ocorrerão na área de influência da atividade transformadora, em decorrência da introdução de ao menos uma intervenção ambiental (Kohn de Macedo, 1994).

Os Fenômenos Ambientais (FEAs) consistem na transformação do comportamento e/ou funcionalidade pré-ocorrentes de um ou mais fatores ambientais, em decorrência de ao menos uma alteração ambiental (Kohn de Macedo, 1994). Deste modo, os FEAs constituem-se os impactos ambientais propriamente ditos (Crestani, 2002). Os fenômenos são caracterizados através do desempenho dos fatores ambientais por eles impactados, constituindo o conjunto chave da gestão ambiental e dos processos de avaliação de impactos (Kohn de Macedo, 1994).

A partir dos eventos ambientais identificados, foram atribuídas relações de causa e efeito entre estes eventos, que foram organizados em forma de fluxograma, construindo-se assim, uma árvore de eventos denominada de Fluxo Relacional de Eventos Ambientais (FREA). Este fluxograma estabelece de forma clara as relaçôes de causa e efeito, permitindo desta forma as discussões somente dos pontos considerados de maior importância para o empreendimento e a área de estudo em questão. Através das representaçôes gráficas referentes aos FREAs de cada uma das intervenções ambientais, a visualização da relação causa e efeito entre os eventos é mais facilmente observada (Kohn de Macedo, 1994).

Assim, através da identificação dos eventos ambientais (conjunto de todas as intervençôes, alteraçōes e fenômenos ambientais) decorrentes da atividade, em cada um dos meios, elaborou-se a Hipótese Global de Situação de Impacto - HGSI. Caso o empreendimento ou atividade sob avaliação já exista, como é o caso, a HGSI representa a imagem do quadro ambiental ocorrente, e portanto não se trata de um projeto a ser viabilizado, mas sim um conjunto de processos, atividades, produtos e serviços operacionalizados a serem ambientalmente otimizados em termos de seu desempenho ambiental (Kohn de Macedo, 1994).

Todos estes elementos preconizados pelo MAGIA, como os FREAs, HGSIs e outros, foram obtidos através do software IDEA, que atua como um banco de dados, onde se trabalha estas informaçôes com maior agilidade e organização (Crestani, 2002).

\section{RESULTADOS}

Ao todo foram identificados três intervenções ambientais (INAs), que resultaram sete alteraçôes ambientais (ALAs), que tiveram como consequência 17 fenômenos (FEAs) ou impactos ambientais, sendo cinco deles no meio físico, três no meio biótico, e nove no meio sócio-econômico.

O fluxograma (FREA) elaborado (Figura 2), considerou as três intervenções identificadas como ponto de partida, e relacionou-as com as alterações ambientais analisadas. Cabe ressaltar que algumas das alterações identificadas são comuns a mais de uma intervenção, o mesmo acontecendo, com os fenômenos ambientais ou impactos, em relação às alterações ambientais. Isto demonstra as inter-relações entre os eventos ambientais (INAs, ALAs e FEAs), e que na prática, a utilização dos FREAs funciona como um elemento facilitador para a gestão de impactos, uma vez que as interaçôes causa-efeito ficam bem estabelecidas.

\section{Discussão}

$\mathrm{O}$ parque industrial pesqueiro de Itajaí e Navegantes apresenta três intervenções ambientais (INAs), a saber, desembarque (INA 1), observadas em empresas de captura e beneficiamento; processamento (INA 2), observado em empresas de beneficiamento; e comercialização (INA 3), observado tanto em empresas que trabalham diretamente com comercialização, como em empresas de captura, e de beneficiamento (Figura 2).

A maioria das alteraçōes (aspectos) ambientais (ALAs) consideradas decorre das três INAs identificadas (Figura 2). A geração de empregos (ALA 1), diretos e indiretos está presente no desembarque, no processamento e na comercialização do pescado. Entretanto, a sazonalidade da produção, gera impactos ou fenômenos antagônicos com o aumento de empregos (FEA 1), nos períodos de safra, e a diminuição de empregos (FEA 2), nos períodos de entressafra da pesca. Verifica-se também que estas três intervençôes propiciam a indução ao dinamismo econômico (ALA 2), cujos impactos decorrentes desta alteração encontram-se associados ao aumento do aporte de tributos (FEA 3) nas municipalidades, e ao aumento da geração de renda (FEA 4), no comércio local (Figura 2).

A geração de efluentes com descarte sem tratamento no rio (ALA 3) também está associada às três intervençōes identificadas, e decorre a partir da manipulação do pescado, e também dos processos de limpeza, com o uso de detergentes. $\mathrm{Na}$ maioria dos casos estes efluentes são descartados diretamente no rio, sem tratamento prévio, resultando na redução da qualidade da água (FEA 5) do rio, uma vez que aumenta a quantidade de matéria orgânica e substâncias químicas despejadas no corpo receptor. Em decorrência deste impacto, outros impactos podem ser gerados tais como a modificação na abundância e diversidade da biota aquática (FEA 6), que reflete na perda de espécies de interesse ecológico-econômico (FEA 7), e a modificação da paisagem (FEA 8), que tem como conseqüência a redução do interesse turístico (FEA 9) da região (Figura 2).

Outra alteração identificada que também decorre das três intervençōes, é a geração de resíduos sólidos (ALA 4), que são cabeças, vísceras, escamas, nadadeiras e espinhos de peixes, óleos do pescado, carapaças e cabeças de crustáceos, vísceras de moluscos, e mais todo tipo de pescado fora do padrão de qualidade exigido no mercado, que são descartados muitas vezes diretamente no rio. A ineficiência no uso pleno da matéria prima com o descarte destes resíduos sendo feito nos cursos d'água, desencadeia os mesmos impactos identificados anteriormente, relativos à redução da qualidade da água (FEAs 5 a 9).

Também identifica-se o aumento da pressão em unidades de disposição de resíduos sólidos (FEA 11), como por exemplo os aterros sanitários. Os resíduos de pesca classificam-se como 


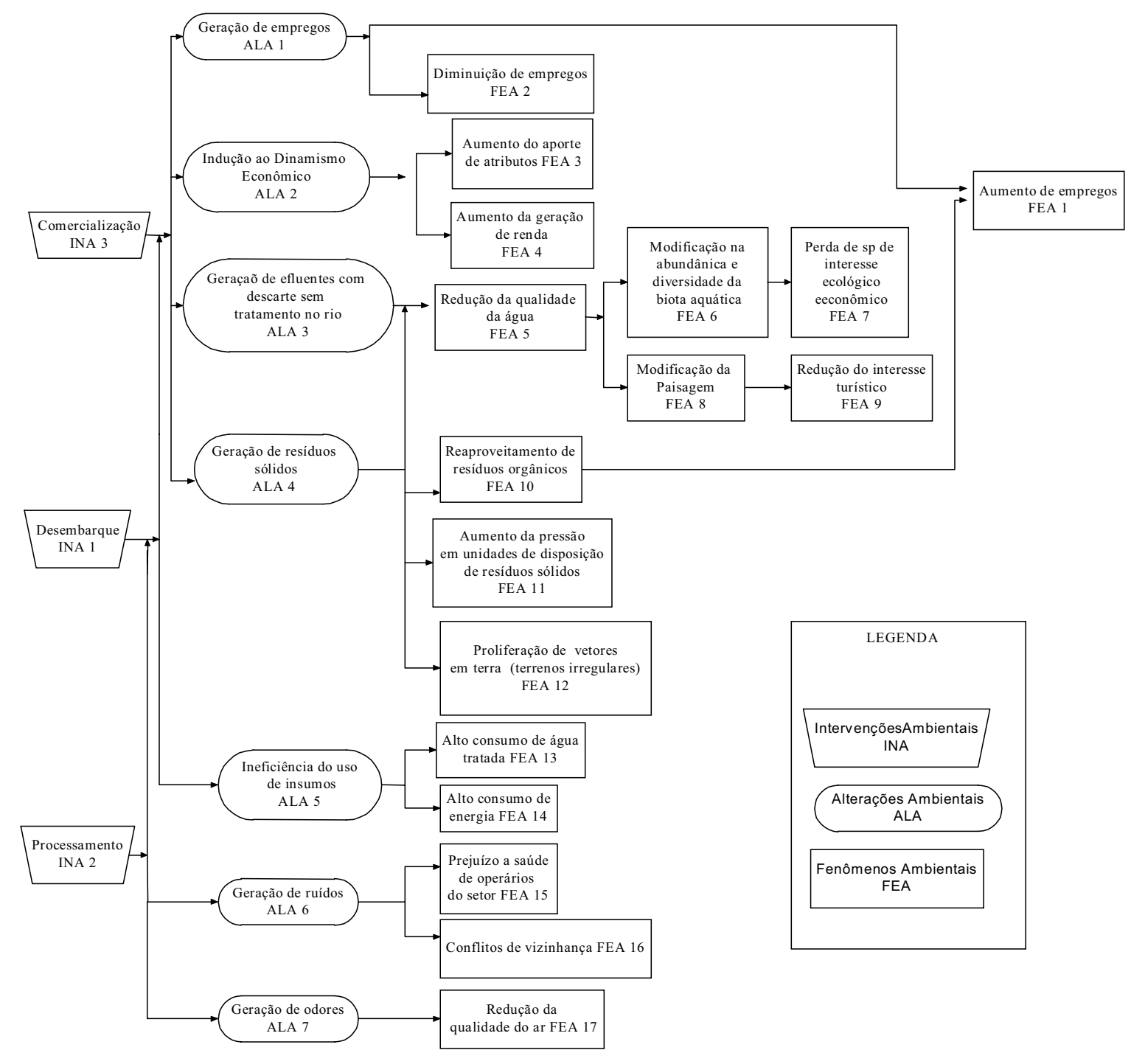

\section{Figura 2 - Fluxograma relacionando os eventos ambientais da hipótese global de situação de impacto para o parque industrial pesqueiro de Itajaí e Navegantes, indicando as intervenções (INAs), alterações (ALAs) e fenômenos (FEAs) ambientais}

Classe I - Perigosos (resíduos de pescado contaminados); ou Classe II - Não inertes (resíduos de pescado não contaminados), de acordo com a NBR 10004 (ABNT, 1987). Assim os resíduos quando não aproveitados devem ser direcionados ao aterro industrial, localizado em Blumenau. Em alguns casos, isto não ocorre, sendo estes resíduos descartados em locais de situação irregular, acarretando mais um impacto identificado como proliferação de vetores em terra (terrenos irregulares) (FEA 12), que podem transmitir doenças na população local. Entretanto, quando ocorre o reaproveitamento de resíduos orgânicos (FEA 10), estabelece-se uma cadeia de impactos positivos, resultando inclusive no aumento da oferta de empregos (FEA 1) por parte da indústria farinheira (Figura 2).
Em paralelo à ineficiência do uso de matérias primas, está a ineficiência do uso de insumos (ALA 5), decorrente das tarefas de desembarque e processamento. $\mathrm{O}$ alto consumo de água tratada (FEA 13), assim como o alto consumo de energia (FEA 14), utilizadas principalmente no congelamento, nas máquinas de processamento e na estocagem dos produtos, são resultados da falta de planejamento e gerenciamento destes recursos, observada na maioria das empresas pesquisadas. Sobre estes aspectos também verificou-se o uso excessivo de cloro na água. O cloro utilizado na água para lavagem do pescado, acaba ficando em contato direto com os manipuladores, que de uma maneira geral não utilizam equipamentos de proteção individual. Durante as visitas foi relatado que invaria- velmente estes trabalhadores reclamam de ardência nos olhos e alergia na pele.

Associada às tarefas do beneficiamento, foi identificada a geração de ruídos (ALA 6), que além de gerar prejuízos à saúde de operários do setor (FEA 15), provocam conflitos de vizinhança (FEA 16), que também é de outra alteração, geração de odores (ALA 7), e outro impacto, a redução da qualidade do ar (FEA 17).

Apesar deste quadro apresentar um maior número de impactos adversos, algumas medidas para mitigação e/ou compensação destes impactos, são de simples e fácil implantação. Dentre elas destacam-se a construção de estaçóes de tratamento, o monitoramento ambiental, o aproveitamento dos resíduos sólidos, a capacitação de 
funcionários, o uso de equipamentos de segurança, o planejamento de produtos mais elaborados (agregando valor ao produto), e utilização de técnicas modernas, assim como uma conscientização do empresariado pesqueiro em relação ao novo consumidor, que além do cuidado na escolha de produtos, preferem produtos que náo causem danos ao meio ambiente.

Ficou evidente a necessidade de modificar; ampliar a linha de produtos para agregar valor, diminuindo-se a ociosidade do setor e garantindo maior consumo de pescados pelo mercado. Além disso, fica clara a necessidade de mudança do setor, aplicando-se as práticas da gestão ambiental nestas empresas visando à melhoria contínua de produtos, a adequação de efluentes e ao novo pensamento do mercado consumidor.

\section{CONCLUSÕES}

A partir do quadro levantado para o setor pesqueiro considerando-se as intervenções, alterações e fenômenos ambientais, estabeleceu-se como Hipótese Global de Situação de Impacto - HGSI, que as alterações e fenômenos ambientais gerados pelas atividades da indústria pesqueira são decorrentes da falta de planejamento da indústria, e da falta de interesse destas indústrias em querer se adequar aos procedimentos atuais de saúde, segurança e meio ambiente. Os impactos ambientais identificados são em sua maioria negativos, enquanto os impactos positivos estão associados a aspectos sócio-econômicos nas cidades de Itajaí e Navegantes, que mesmo apresentando eventos de desemprego na entressafra, contribuem durante todo o ano com a oferta de empregos para a população. A situação ambiental na grande maioria destas empresas é irregular, e existem evidências de que não há interesse em se estabelecer mudanças nas práticas verificadas. As mudanças ocorrerão se existirem maiores exigências por parte das agências fomentadoras deste setor, dos órgãos ambientais e da própria sociedade. Desta forma, as empresas serão obrigadas a adequar seus procedimentos a estas exigências.

Portanto, observa-se a necessidade de uma orientação voltada à gestão ambiental, devido à falta de procedimentos relacionados à saúde, segurança e meio-ambiente, verificada nestas empresas. Espera-se com isso reduzir a poluição da água e do ar, e dos resíduos orgânicos, potencializar os usos da matéria prima e insumos, aumentar o lucro e a produtividade das empresas, aumentar a satisfação e qualidade de vida dos trabalhadores do setor e da comunidade adjacente a estes empreendimentos, atingindo-se assim uma melhor eficiência do setor e conseqüentemente a qualidade ambiental do território e das pessoas que direta ou indiretamente estão associadas ao setor pesqueiro.

\section{AGRADECIMENTOS}

À Pró-reitoria de Pesquisa, Pósgraduação, Extensão e Cultura Proppec da Universidade do Vale do Itajaí - UNIVALI, pela concessão da Bolsa do Programa Integrado de Pós Graduação e Graduação - PIPG. A Rômulo Pazzinato Jr. pela dedicação e esforço. Os autores reconhecem o pioneirismo de Ricardo Kohn de Macedo em propôr uma abordagem para gestão e avaliação de impactos ambientais, e o mérito de Fernando Penna Botafogo Gonçalves em liderar e formar um grupo de profissionais, estabelecendo elevados padróes técnicos, e sobretudo éticos, na condução de estudos de impactos ambientais.

\section{REFERÊNCIAS}

ABNT - Associação Brasileira de Normas Técnicas. NBR 10004: Classificação de Resíduos Sólidos. Rio de Janeiro: ABNT, 1987.

CRESTANI, D.E.V. Proposição de uma hipótese preliminar para a implantação e a operação de uma marina no Saco da fazenda, Itajai, SC. Monografia (Graduação em Oceanografia). Universidade do Vale do Itajaí - UNIVALI. Itajaí, 2002.

KOHN DE MACEDO, R. Gestão ambiental: os instrumentos básicos para a gestão ambiental de territorios e de unidades produtivas. Rio de Janeiro; ABES; 266 p. 1994.

PROMAR. Relatório de Impacto Ambiental para a implantação e operação do Estaleiro Aker Promar - RIMA. Itajaí, 2004

REBELO NETO, J. R. Perfil do setor pesqueiro na foz do Rio Itajai Açu. Itajaí. 1989.

SOBRAL, M.C.M. et al. Gerenciamento dos Riscos Ambientais em Indústria de Cerâmica Esmaltada. In: XI SIMPÓSIO LUSO BRASILEIRO DE ENGENHARIA SANITÁRIA E AMBIENTAL, Natal, 2004. Anais - Natal - RN: ABES, p. 137.2004 .

Endereço para correspondência:

\section{Luciana de Carvalho Spillere Laboratório de Estudos de Impactos Ambientais UNIVALI \\ Rua Uruguai, 458}

88302-202 Itajaí - SC - Brazil

Email: luciana.spillere@ibama.gov.br

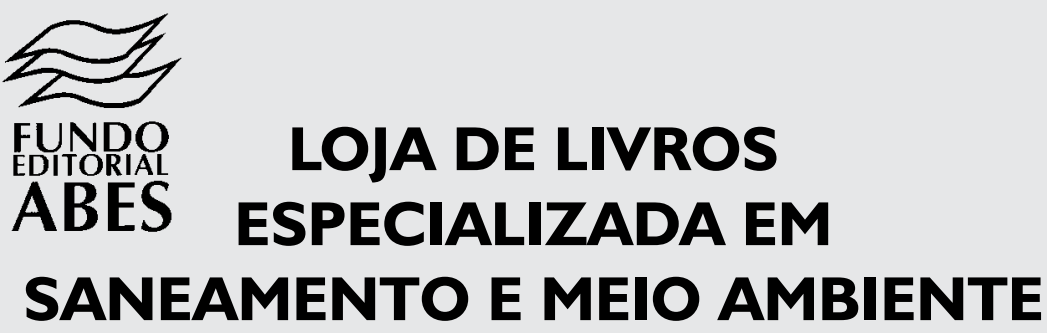

\author{
Listagem organizada por assunto e tabela de preços \\ www.abes-dn.org.br
}

